\title{
Artículo de investigación
}

\section{La historia de las personas afrocolombianas a partir de las ilustraciones contenidas en los textos de Ciencias Sociales para la Educación Básica'}

\begin{abstract}
RESUMEN
Este artículo explora la imagen que se asocia con las comunidades afrocolombianas en los textos de Ciencias Sociales para la Educación Básica. La investigación en la cual se sustenta indagó sobre algunos elementos de permanencia, cambio, continuidad y discontinuidad alrededor de la imagen que se difunde de las y los afrocolombianos en los textos escolares de Ciencias Sociales, especialmente en lo relativo a la presencia 0 ausencia de este grupo, que representa un $26 \%$ de la población colombiana, y sobre el cual pesan ancestrales estereotipos, con el objeto de establecer los prejuicios y estereotipos que se hacen evidentes en los textos. El análisis es de tipo descriptivo y destaca la necesidad de contar con elementos de juicio. a la hora de seleccionar los textos escolares.
\end{abstract}

\section{Palabras clave}

Iconografía escolar, textos o manuales escolares, racismo, Ilustración, topografía moral, afrocolombianidad, hiștoria de la resistencia.

Cátedra de Estudios Afrocolombianos (CEA).
María Isabel Mena García

afromena@yahoo.com

\section{ABSTRACT}

This article explores the image that is associated with the afrocolombian communities in texts of Social Sciences for the Basic Education. The investigation in which it is sustained investigated on some elements of permanence, change, continuity and discontinuity around the image which it spreads of and the afrocolombians in scholastic texts of Social Sciences, specially with respect to the presence or absence of this group, that represents a $26 \%$ of the Colombian population, and on which weigh ancestral stereotypes, with the intention of establishing the prejudices and stereotypes that become evident in texts. The analysis is of descriptive type and emphasizes the necessity to count on elements of judgment at the time of selecting scholastic texts.

\section{KEY WORDS} Scholastic iconography, texts or manual students, racism, illustration, moral topography, afrocolombianity, history of the resistance.

Afrocolombian Chair of Studies (CEA).

RECBBIDO: MARZO 2006 • ACEPTADO: ABRIL 2006

1 El artículo presenta resultados parciales de la tesis de Maestría en Investigación Social Interdisciplinaria, titulada "La Historia que cuentan las imágenes de los afrocolombianos y afrocolombianas, en los textos escolares de Ciencias Sociales", desarrollada entre los años 2005 y 2006.

2 Licenciada en Historia, de la Universidad del Valle. Magíster en Investigación Social Interdisciplinaria, de la Universidad Distrital. Becaria del Fondo condonablé Icetex. Miembro de la Consultiva Distrital de las Comunidades Afros. 


\section{Introducción}

L

a exploración e interpretación de las imágenes que en los textos de Ciencias. Sociales que circulan en Colombia aparecen asociadas con las comunidades afrocolombianas permiten develar los prejuicios y estereotipos que socialmente se han construido y difundido el contexto de la escuela. Tales categorías de análi-. sis están relacionadas con varias dimensiones.

Una dimensión investigativa, expresada en el escaso o nulo conocimiento elaborado en nuestro medio sobre el tema de África, los africanos y sus descendientes, que no se han constituido para la Academia Colombiana y especialmente para los investigadores sociales en un campo fértil de investigación ${ }^{3}$.

Una dimensión educativa, consecuencia de la anterior, y que se manifiesta en el escaso reconocimiento por parte del sistema educativo sobre el papel de la trata trasatlántica, la diáspora africana y la situación actual de las poblaciones afrocolombianas como trazas complejas y específicas de los fundamentos de la identidad colombiana. Por consiguiente, "la enseñanza humanística en el ámbito de la Educación Superior en Colombia se desenvuelve a espaldas de las dinámicas y de los logros alcanzados por el africanismo y por los estudios afrocolombianos. Por ende, esa idea central también supone que el conocimiento y la percepción que se tiene en Colombia respecto de África están copados por la ignorancia, el prejuicio y las miradas excluyentes heredadas de los discursos propios de la colonialidad"4.

En ese marco de la invisibilidad de las comunidades afrocolombianas en la historia de este país, se conjugan distintos mecanismos para hacer que la ilustración que aparece en las cartillas o manuales escolares esté provista de una carga muy

3 A pesar de la existencia de un péqueño grupo de activistas, militantes, investigadores y personàs solidarias con la causa.

4 Díaz Díaz, Rafael Antonio (2006) África, africanismo y los estudios afrocolombianos en las Ciencias Sociales en Colombia: realidades, retos y perspectivas. En proceso de publicación. Universidad Javeriana, Bogotá. fuerte de racismo ${ }^{5}$ en su contenido visual. Esta situación persiste a pesar de la obligatoriedad de la enseñanza đ̂el África, instaurada desde 1993 y reglamentada a partir de 1998. Por lo tanto, para la implementación de la Cátedra de Estudios Afrocolombianos $(\mathrm{CEA})^{6}$, es perentorio contar con textos escolares idóneos que den soporte a las necesidades didácticas que se derivan de la inclusión del África, los africanos y sus descendientes en el currículo oficial.

El uso del texto escolar de Ciencias Sociales en un país reconocido como multiétnico y pluricultural, abre paso al requerimiento de analizar en profundidad la iconografía que acompaña sus imágenes sobre las comunidades afrocolombianas en los manuales escolares ${ }^{7}$. En consecuencia, la dimensión iconografía fue el objeto de la investigación cuyos resultados se configuran en el presente documento. Tales imágenes se interpretan desde los planteamientos de teóricos como Foucault (2004), van Dijk (1997) y Bordieu (1995), a partir de quienes se realiza el análisis correspondiente. Se parte de la consideración de que esas imágenes se constituyen en la memoria visual desde la cual han aprendido generaciones tras generaciones a leer un orden social.

La indagación se realizó sobre la iconografía escolar, compartiendo que las ilustraciones son multimodales, es decir, que los elementos que las acompañan deben observarse en sus múltiples componentes y analizados de manera integral. Para efectos de este trabajo, es de interés especial el tipo de historia que se cuenta a través de las ilustraciones y los mecanismos que se activan para que esas imágenes expresen un contenido histórico. Para ello se tienen presentes los conceptos de Ilustración, topografía moral, afro-

\footnotetext{
5 El racismo es una doctrina que refiere una concepción mediante la cual los seres humanos son clasificados y ubicados socialmente de acuerdo con el tipo racial al que pertenecen.

6 La CEA es un mandato nacional según el Decreto 1122 de 1998, mediante el cual se crean las condiciones institucionales para que las comunidades educativas conozcan y se apropien, entre otros elementos, del reconocimiento de los aportes a la historia y a la cultura colombiana realizados por las comunidades afros.

7 Los textos seleccionados fueron Orígenes para los grados 4,5 , y Horizontes sociales para el grado 3.
} 
colombianidad e historia de la resistencia; que ayudan en la comprensión de las ilustraciones sobre los afros.

La Ilustración o el movimiento de los "ciudadanos ilustrados", surge en el siglo XVIII como expresión del pensamiento o de la racionalidad moderna. Autores como Montesquieu, Voltaire y Diderot ${ }^{8}$ construyeron un cuerpo argumentativo y una metodología basada en el método cartesiano que propendía, entre otros aspectos; por jerarquizar a los seres humanos de acuerdo con el tipo racial al cual pertenecían. Para efectos de esta investigación, se considera que a partir de esta concepción es como los seres humanos serán dibujados en los textos escolares, desde la lejanía o proximidad a la persona considerada "clásica", entendiendo por éste al tipo blanço, caucásico y hombre. Ejemplo de esta concepción es la famosa pirámide social con la cual se ha enseñado y aprendido, a lo largo de muchas generaciones el orden social de la sociedad colonial.

Zenaida Osorio plantea esta situación en los siguientes términos: "Las personas de la iconografía escolar surgen como personas: ilustradas en un doble sentido, por lo menos el primero y visual, en cuanto están ilustradas, es decir, están ahí puestas al alcance de los ojos de los niños y las niñas, en las páginas de las cartillas en las que confía la visión adulta y por ello lleva doscientos años recomendándolas y avalándolas como buenas para los ojos escolares. El segundo, son ilustradas en el sentido que les otorga la ilustración: son imágenes de personas a través de las cuales se formuló a finales del siglo XVIII y se fijó durante todo el XIX, un repertorio que permitió clasificar a los seres humanos en tipos jerarquizados".

Estas reflexiones sobre la racialización o Ilustración de la sociedad nos llevan a la segunda referencia necesaria para el acercamiento a las imágenes de los afrocolombianos. Se trata de la perspectiva de las imágenes dominantes que tiene que

8 Brion, David (1996) "El problema de la esclavitud en la cultura occidental”. El Áncora Editores. Universidad de los Andes:383-385.

9 Osorio Porras, Zenaida (2001) Personas ilustradas, la imagen de las personas en la iconografía escolar. Colciencias - FES, Bogotá: 10. ver con la topografía moral y la visión que construyó el mundo español o "blanco" sobre los mestizos, indígenas, los africanos y sus descendientes.

La referencia sobre la ilustración establece que el concepto racial determinó el orden social establecido por la sociedad colonial el cual, de alguna manera, continúa vigente hasta nuestros días. La topografía moral consistente en una geografía de la cultura, refuerza el análisis mediante el cual lo racial y la cultura, están mediados por las características geográficas. Estas relaciones serán objeto de reflexiones comó la de Taussig, quien señala:

La Geografía es también un mapa de la historia social y una carta cosmológica representada en topografía (...) espacio físico, es también espacio semántico. Esta geografía no es espacio cultural neutral sino que se deriva de las ideologías y de los discursos dominantes que tienen un estatus hegemónico, puesto que han sido propagadas por las clases y regiones más poderosas del país. La topografía moral no es sólo un mapa mental sino que se inscribe en un mosaico de diferencias articuladas en las cuales cielo e infierno, virtud y corrupción, distinciones de casta y clase y la función mnemotécnica del paisaje sosteniendo la memoria colectiva ${ }^{10}$.

Esta representación de la condición climática y de su consecuencia en el mundo colonial atraviesa la producción de los pensadores del siglo XIX, quienes le adjudicarán al clima, a los terrenos agrestes y selváticos $\mathrm{y}$, por supuesto a sus pobladores "salvajes", la justificación de un subdesarrollo y de un atraso pensado desde la metrópoli. Por tal razón esas condiciones debían desaparecer para que la nación diera el salto necesario hacia la modernidad. Este planteamiento es señalado por el profesor Serna en los siguientes términos: "La ficción geográfica colonial, urdida en aquella topografía moral que superpuso paisaje, raza y moral se perpetuó en los siglos subsiguientes: un recurso que afianzó

10 Taussaig, Michel (2002). Chamanismo, colonialismo y el hombre salvaje. Un estudio sobre el terror y la curación. Grupo Editorial Norma. Bogotá:220. 
un régimen identitario que permitió jerarquizar el territorio colonial entre cordilleras, vertientes y selvas y con ello legitimó la ascendencia natural de unos grupos sociales sobre otros, cada uno de ellos marcado por profundas connotaciones étnicas"11.

A propósito de la actual discusión sobre los órdenes raciales, es sorprendente ver cómo las investigaciones del mapa o genoma humano no han incidido en la forma como los textos repre-: sentan a las personas. En otras palabras, no existe en los textos analizados una traducción o mediación de los hallazgos de distintas disciplinas como la Antropología, la Genética o la Historia; para mejorar o por lo menos actualizar lo que se dice frente a la gente afrocolombiana. Por tal razón, "La conclusión de que todos los seres humanos son afrodescendientes, 'volvió a encender la llama de la discusión después de los hallazgos del genoma o mapa humano.

Estas investigaciones, además de demostrar un antepasado común africano, lo que coloca al continente africano como la cuna de la hominización, han mostrado cómo hay mayor afinidad genética entre dos seres étnicamente distintos que dos corraciales y ayuda a desmitificar la superioridad racial que configuró el tema de las relaciones sociales en los países de América Latina"12. Si bien es lenta la comprensión y asimilación de novedosas perspectivas sobre el mundo africano, es hora de incorporar en los textos escolares esas posibilidades de abordajes historiográficos. Por consiguiente, estas dos referencias: la Ilustración y la Topografía moral, sirven de marco para interpretar las imágenes sobre la gente afro en Colombia y a las cuales se agrega una tercera categoría que permite situar en el presente las imágenes escolares. Se trata de las versiones sobre la resistencia y que en este trabajo se denomina la Historia de los vencidos. Esta perspectiva se propone contar de otra manera la poderosa historia escolar.

\footnotetext{
${ }^{11}$ Serna Dimas, Adrián (2006). Ciudadanos de la geografía tropical. Ficciones históricas de lo ciudadano. Fondo Editorial de la Universidad Distrital. Bogotá:288).

${ }^{12}$ Mena María Isabel (2005): Afroamericanidad y afrocolombianidad. Biblioteca de Ciencias Sociales. Editorial Voluntad: Bogotá:10.
}

Para acceder a la perspectiva sobre la Historia de la resistencia o la Historia de los vencidos, es necesario hacer referencia al concepto propuesto por Wachtel en su investigación sobre los aborígenes del Perú. Al respecto, plantea: "Se trata, en cierto modo de pasar al otro lado del escenario y escrutar la historia al revés, por qué estamos efectivamente acostumbrados a considerar el punto de vista del europeo como el derecho en el espejo indígena se refleja el otro rostro de occidente. Sin duda, jamás podremos revivir desde el interior los sentimientos y los pensamientos de Moctezuma`o Atahualpa.

"Las personas de la iconografía
escolar surgen como personas
ilustradas en un doble sentido,
por lo menos el primer visual, en
cuanto están ilustradas, es decir,
están ahí puestas al alcance de
los ojos de los niño y las niñas".

Pero podemos, al menos desprendernos de nuestros hábitos mentales, desplazar el punto de observación y transferir el centro de nuestro interés a la visión trágica de los vencidos"13. La posibilidad de trabajar desde la visión de los vencidos se convierte en una apertura teórico-metodológica para interrogar la iconografía escolar y los metarrelatos allí establecidos. La conjunción de lo visual con el mensaje explícito o implícito en las imágenes se convierte en la materia prima para comprender las representaciones que están ilustradas de las comunidades afrocolombianas en los textos escolares.

La última referencia, la afrocolombianidad, expresa un concepto bastante polémico y que se encuentra en proceso de construcción por parte de una fracción del movimiento social afrocolombiano, mediante el cual se pretende reemplazar el etnónimo "negro", con el cual los europeos designaron a hombres y mujeres cazados en las cos-

\footnotetext{
${ }^{13}$ Wachtel Nathan (1976) "Los vencidos. Los indios del Perú frente a la conquista espáñola (1530-1570. Alianza Editorial:24.
} 
tas africanas. Su objetivo consiste en evidenciar que si del África llegaron africanos, sus descendientes no podrían ser negros sino precisamente afroamericanos $y$, más preciso, afrócolombianos. El debate sobre el nombre de ese grupo humano pasa por el reconocimiento a la verdad, al conocimiento de esa parte de la historia $y$, por supuesto, a la exigencia de las reparaciones ${ }^{14}$ que se deriven del caso.

Por el contrario, otra fracción del movimiento social afrocolombiano cree en la reivindicación del término negro-a, ya que en eso se convirtieron los africanos una vez cayeron bajo la condición de esclavizados. Para este grupo es posible cambiar la connotación del término que tradicionalmente ha sido asociado en el mundo judeo-cristiano con lo malo y lo oscuro, por un eslogan como: "por un futuro negro y bonito". El debate apenas empieza. Mosquera lo sitúa en estos términos: "Debemos despojarnos de la mentira de que "los negros llegaron de África. De África llegaron las personas africanas, tenían dignidad y tenían identidad cultural, una compleja identidad cultural. Existe la necesidad de ayudar a nuestros pueblos a liberarse mentalmente de la condición de negros"15. Frente a este debate, que muchos consideran de poca importancia, véase la interesante investigación de los autores (Gregory Lobo y Nick Morgan 2003) que lleva como título: Lo decimos con cariño: estratificación racial y el discurso de lo negro en Colombia ${ }^{16}$.

${ }^{14}$ La reparación es un mecanismo mediante el cual los estados que tuvieron población esclavizada equilibran, a partir de medidas especiales, las condiciones bajo las cuales quedan estas personas cuando es abolida la esclavización, las llamadas acciones afirmativas son un ejemplo de la reparación histórica.

${ }^{15}$ Mosquera Juan de Dios (2004). Integración de la afrocolombianidad al sistema educativo nacional. En memorias de encuentro en la diversidad. Museo Nacional. Bogotá:15.

${ }^{16} \mathrm{E} 1$ argumento fuerte de esta ponencia es la resistencia por parte de la sociedad colombiana a reconocerse como una comunidad racista. Según los autores es un proceso donde se ven cambios. Pero para lograr cambios tiene que haber intervenciones más bien que una aceptación pasiva por parte de las instituciones culturales de un orden racista. Aunque hay activistas y movimientos que luchan en contra del racismo, todavía es poco común que los colombianos que no se consideren de ascenden-

\section{Metodología}

En los últimos tiempos se ha fortalecido desde las Ciencias Humanas y Sociales el uso de técnicas híbridas. Tal es el caso de la presente investigación en la que se incorporaron tanto metódicas de raigambre foucaultiana como propuestas de Análisis de Contenido y en especial del análisis Crítico de Contenido (ACD). Este último en cuanto se relaciona con el poder, el abuso de poder y con la producción y reproducción de éstos en los textos orales y escritos. El ACD se enfoca en los grupos e instituciones dominantes y en la forma en que éstos crean y mantienen la desigualdad social por medio de la comunicación y el uso de la lengua ${ }^{17} \mathrm{Al}$ respecto, este autor señala que: " $\mathrm{El}$ análisis crítico del discurso se ocupa fundamentalmente del tipo de abuso de poder a través del discurso, por ejemplo, cuando los libros de texto, artículos de prensa o discursos políticos son usados para difundir prejuicios racistas o sexistas" (Ibíd.: 6).

Con esta metodología de naturaleza multidisciplinar y teniendo presente los hallazgos realizados por Zenaida Osorio ${ }^{18}$ y Sandra Soler ${ }^{19}$, respectivamente, se situaron los temas asociados a la imagen afrocolombiana. Las etapas, grosso modo, fueron: primero, una selección de los textos escolares que circulan con mayor fuerza entre los docentes del sector público en Bogotá; en un segundo momento se emprendió la lectura de las imágenes y su organización temática; posteriormente se procedió a la identificación de posibles. patrones o atributos de análisis; y finalmente se realizó la comparación entre los diferentes textos escolares seleccionados para determinar la permanencia o el cambio en las imágenes utilizadas.

\footnotetext{
cia afro tengan en cuenta las implicaciones de las palabras que dicen "automáticamente" y su relación con una verdadera situación de discriminación en el país.

17 Van Dijk, Teun A. (1997). Racismo y análisis crítico de los medios de comunicación. Ediciones Paidós. Barcelona:8,16.

18 Osorio Porras, Zenaida (2001). Personas ilustradas, la imagen de las personas en la iconografía escolar. Colciencias - FES, Bogotá.

${ }^{19}$ Soler Castillo, Sandra (2005). Racismo y discurso en los textos escolares. La representación de la diversidad étnica en los textos de Ciencias Sociales en Colombia. En proceso de publicación. Universidad Distrital.
} 
En.las ilustraciones. seleccionadas se relevó la distribución espacial de la gente afrocolombiana. En consecuencia, aspectos como las ropas, la disposición corporal, la simbología asociada a la corporalidad, las tareas $u$ oficios que se evidencian en el contexto de la imagen, dieron cuenta de las temáticas asociadas a las imágenes. Éstas fueron leídas y releídas y la mayoría de ellas comentadas con docentes y estudiantes de colegios oficiales.

Los manuales escolares se seleccionaron con base en los datos aportados por la Secretaría de Educación de Bogotá D.C., a través del proyecto Vitrina Pedagógica, teniendo en cuenta aquellos que circulan con mayor demanda. Por lo tanto, se eligió el sector público debido a que en éste se encuentra la mayoría de la población afro escolarizada. Tal situación señala un sesgo en la muestra, ya que quedaron por fuera los datos provenientes del sector privado. Esta indagación permitió establecer que los tres (3) textos más solicitados por los docentes para la Educación Básica son: Orígenes para los grados cuarto y quinto de primaria, y $\mathrm{Ho}$ rizontes sociales para el grado tercero.

De este primer registro se seleccionaron las imágenes de los textos Orígenes para cuarto y quinto de primaria, en cuyas páginas aparecen aproximadamente 40 representaciones de los y las afrocolombianas, y se detuvo la mirada sólo en los dibujos, dejando por fuera del análisis las fotografías y otros diagramas por considerar que los primeros tienen un mayor impacto sobre la población escolarizada. Con este filtro se escogieron 16 imágenes (ANEXO 1) de las cuales se analizan dos en las siguientes páginas.

Frente a las condiciones paratextuales de la imagen, hubiese sido muy importante pesquisar la fuente de los dibujos, pero lastimosamente ninguna de las ilustraciones tiene referencia, por lo cual de manera hipotética se concluyó que los dibujos se extraen de Internet, situación que seguramente disminuye los costos y agiliza la edición de un texto escolar.

Un elemento que se resalta es la coincidencia en el papel que cumple la historia escolar como parte de un aparato ideológico, dedicado a fortalecer la imagen de las élites, razón por la cual se les dedica un gran porcentaje de las ilustraciones en los textos escolares, mientras que son escasas las de otros sectores sociales (entre ellos los indígenas, campesinos mujeres $y$, por supuesto, afros) en los distintos períodos históricos.

De allí se infiere la necesidad de orientar a los docentes para que a su vez concienticen a los estudiantes sobre la importancia de conocer acerca de estos ciudadanos; de lo contrario, la historia seguirá siendo invisible y se continuarán contando relatos tergiversados, fracturados e incompletos sobre los afrocolombianos a través de manuales escolares poco pertinentes e inadecuados. Del análisis de esta situación se derivó el siguiente problema: ¿Qué cuentan las ilustraciones contenidas en los textos escolares, sobre la historia de las comunidades afrocolombianas? Este interrogante fue abordado desde los referentes conceptuales anteriormente expuestos y los resultados de dicho análisis se exponen a continuación.

\section{Discusión de resultados}

Los dibujos sobre los afrocolombianos y las afrocolombianas aparecen asociados al mundo colonial y específicamente a la esclavización ${ }^{20}$, inclusive hasta las reformas de 1850, momento en cual el partido liberal asocia el tema de la abolición de la esclavitud a su programa político. Este escenario colonial comporta por lo menos dos cuestiones insalvables para el análisis propuesto. Por un lado, la falta de una historia africana que cuente quiénes fueron ellos antes de la trata, la diáspora y posterior esclavización de los africanos y sus des-

\footnotetext{
${ }^{20}$ Esclavización es más preciso para diferenciar el proceso africano de otros sometimientos como la esclavitud en el mundo antiguo (por ejemplo en la antigua Grecia), a los primeros se les sometió física y mentalmente, se les obligó a cambiar de religión, de nombre, de apellido además de la actuación sobre el convencimiento que eran seres humanos inferiores debido al color de la piel.
} 
cendientes. Por lo menos esta circunstancia abriría la posibilidad de no situarlos exclusivamente en la posición de grupo históricamente vencido.

La otra circunstancia que ponen las imágenes en evidencia es que la trata trasatlántica es un problema de los africanos y no de historia de las colombianos, tema que introduce la distancia como elemento que mantiene alejada la viabilidad de estudiar este capítulo en el contexto de la historia patria.

En consecuencia, es necesario valorar el impacto de estas representaciones en los niños y niñas afros y en general a la población escolarizada a quienes se les cuenta esta historia, puesto que muy seguramente los primeros van a sentir humillación. Se trata de un tema muy delicado en cuanto toca la dignidad de los herederos de esta situación. De ahí la importancia de explicarles el tema de los palenques, el cimarronismo y las luchas libertarias desplegadas por la población africana en la lucha por la libertad. Sin embargo, el bloque de ilustraciones que se presenta en los textos escolares está básicamente asociado con las cadenas, los grilletes y el comercio humano (trata trasatlántica), en tanto estereotipos sociales de la situación histórica mencionada.

A continuación sè pueden apreciar las imágenes propuestas en el texto Orígenes, a propósito de los temas anteriores.

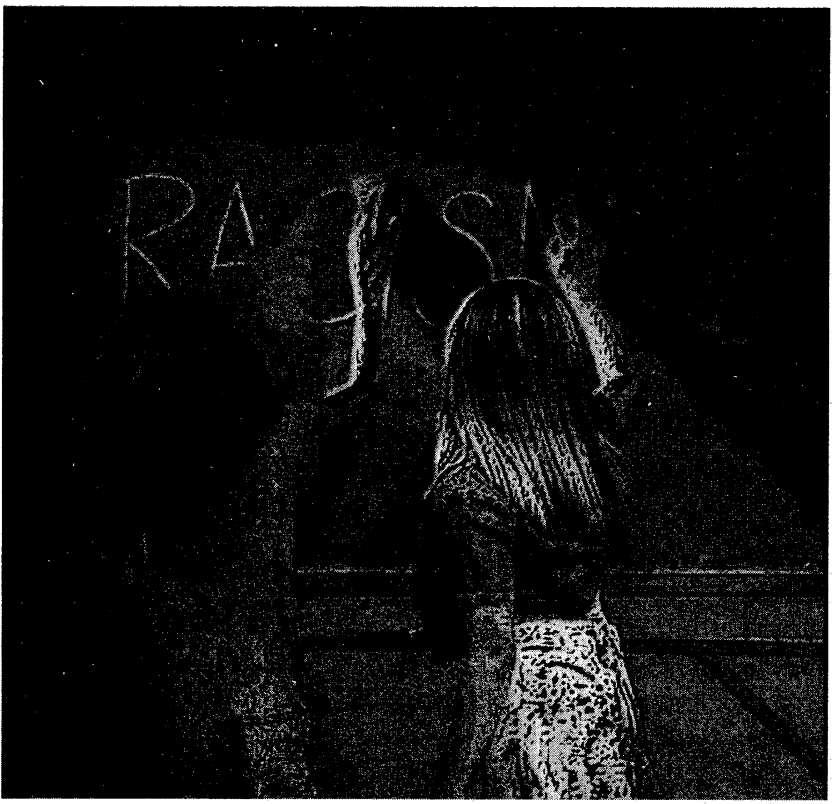

La ilustración 1 representa la acción evangelizadora y doctrinal durante la conquista. La gráfica tiene tres composiciones: 1) un colonizador en actitud de reprensión a un grupo de personas afros, que por la leyenda del texto, se asume que representa a San Pedro Claver; 2) un conquistador en actitud inquisidora frente a un indígena sometido; 3) un sacerdote igualmente en actitud de instrucción religiosa junto a un indígena.

Las composiciones de los sacerdotes se superponen a la composición del colonizador. En cuanto a la construcción de simetrías y lateralidades, las tres composiciones muestran a los colonizadores sobre los colonizados, éstos en actitud sumisa cuando son reprendidos o en actitud atenta cuando son instruidos. En la composición de la población afro, resalta la presencia de la cruz en la mano del sacerdote y de los grilletes en los evangelizados.

En esta gráfica o espectro de composiciones se ponen en evidencia varias temáticas. En primer lugar, se manifiesta la actitud de la conquista, representada básicamente por la disposición corporal y gestùal, tanto del colonizador como del colonizado. En segundo lugar, se destaca la otra cara de esa actitud hostil, la mirada compasiva y comprensiva del colonizador que es sacerdote. En tercer lugar, se enfatiza en unos recursos gráficos para sintetizar la condición o situación colonial: la pasividad indígena o la esclavización africana a través de recursos como los grilletes y la desnudez.

Como se percibe, esta gráfica trae sobre sí toda una serie de discursos sobre el hecho religioso en la situación colonial. En este sentido, es una imagen que tiende a recuperar algunos elementos recurrentes sobre la historia de la religiosidad colonial: la instrucción religiosa como oficio de los conquistadores, la contraposición entre la bondad clerical y la perversidad de los colonizadores, la presencia de la acción religiosa en el trasegar cotidiano, la pasividad y la sumisión del colonizado ante la presencia de lo religioso.

De este modo, la gráfica nos envía a lo común, que no es sino el efecto benéfico de lo religioso en medio de la opresión colonial. Aquí entonces, estamos sobre uno de los discursos más potentes que no sólo incubó la sociedad colonial, sino la misma sociedad colonial: las bondades de 
la religión como un bèneficio de la colonización. Es un discurso reiterativo. Estuvo en las programáticas de los primeros republicanos, se encuentra por ejemplo en idearios como los de Miguel Antonio Caro cerrando el siglo XIX, o actualizado al cierre del siglo $\mathrm{XX}$, a propósito del quinto centenario.

No obstante esta representación, en modo alguno excepcional y por el contrario recurrente en los textos, esconde varias situaciones: a). el efecto desestructurador del discurso religioso católico en los entramados étnicos; b) las formas de articulación y reinvención de complejos mágicos religiosos por parte de los colonizadores; c) la construcción de formas de la vida re- ligiosa que, menos prendadas a la pasividad y a la obediencia, a la asimetría del hombre con el dios, fueron ciertamente activas y contestatarias, producto del hecho de que el dios era ente encarnado sometido a las penurias de los hombres. Este aspecto del dios encarnado, que se muestra en fenómenos como el baile (ritualístico o no), quiebra la representación colonial y nacional de lo religioso. La relación con lo sobrenatural no está mediada por la reverencia pasiva, sino por la reverencia activa en la expresión dancística o musical. Esta parte del hecho religioso colonial está desvanecida de los textos escolares o confinada a eso que se refiere como la cultura, que se enunció en diversos momentos.

\section{llustración 1}

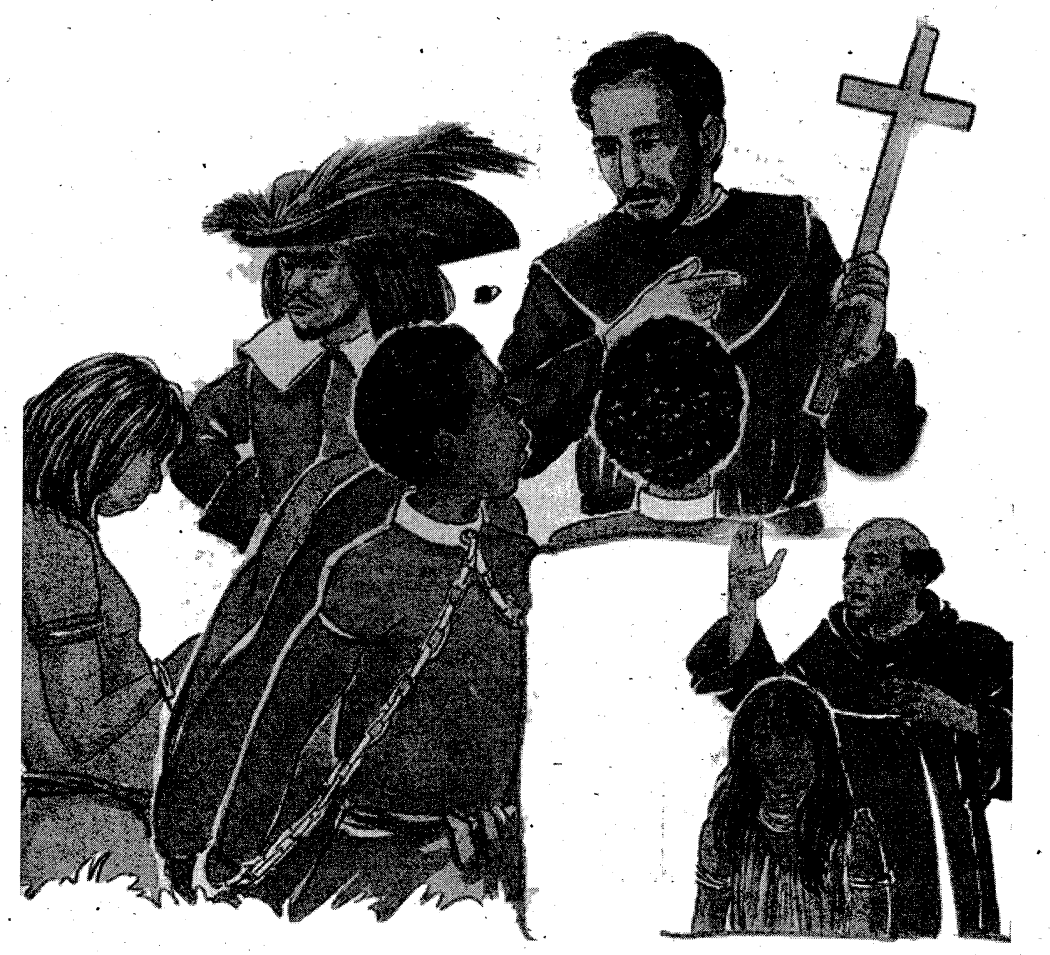

Tomado de Orígenes

Ficha descriptiva

Títulos y subtítulos:

Número de ilustración: 1

Texto de donde se toma la ilustración: Orígenes

Año de edición: 1998

Página donde se encuentra la ilustración: 180

El trabajo esclavo durante la Colonia, La explotación humana durante la Colonia.

Textos escritos asociados a la ilustración:

"Yo soy San Pedro Claver, sacerdote jesuita, nacido en Verdú, España, en 1580. En Cartagena de Indias conocí la crueldad con que eran tratados los negros; me convertí en su protector y amigo. Los ayudé en lo espiritual y económico. Por esto me llamaron el apóstol de los negros". 
Nótese que entre los títulos y la imagen hay una ruptura bastante complicada, la lámina se titula El trabajo esclavo durante la Colonia, pero la imagen corresponde a la iconografía judeo-cristiana explicada anteriormente.

La ilustración trata de representar el universo colonial, logra que la comunidad educativa fije su mirada en las cadenas y los grilletes; sin embargo, la simpleza de la imagen y el texto que la acompaña no logra vincular los diversos órdenes simbólicos que complejizan el universo de la etapa históricamente conocida como la Colonia. Igualmente faltan algunas reflexiones en los textos escolares sobre el significado de los grilletes y las cadenas como mecanismo de domesticación del cuerpo o como marcas distintivas para expre- sar el statu quo de los africanos frente a otras corporalidades que se convierten en textualidades en los manuales escolares. En otros términos, parecería que los grilletes y las cadenas son una prolongación del cuerpo africano.

La ilustración dos se mueve en los mismos órdenes de la imagen anterior, pero además conjuga elementos de la conquista como la figura del conquistador con toda su ornamenta: el caballo, la espada, el tocado en su cabeza. La representación conjuga tres composiciones: 1) un colonizador en actitud vigilante; 2) dos personas trabajando un afro y un indígena; 3) un escenario tal vez de una parcela, ejemplificando el trabajo agrícola que estos últimos realizan.

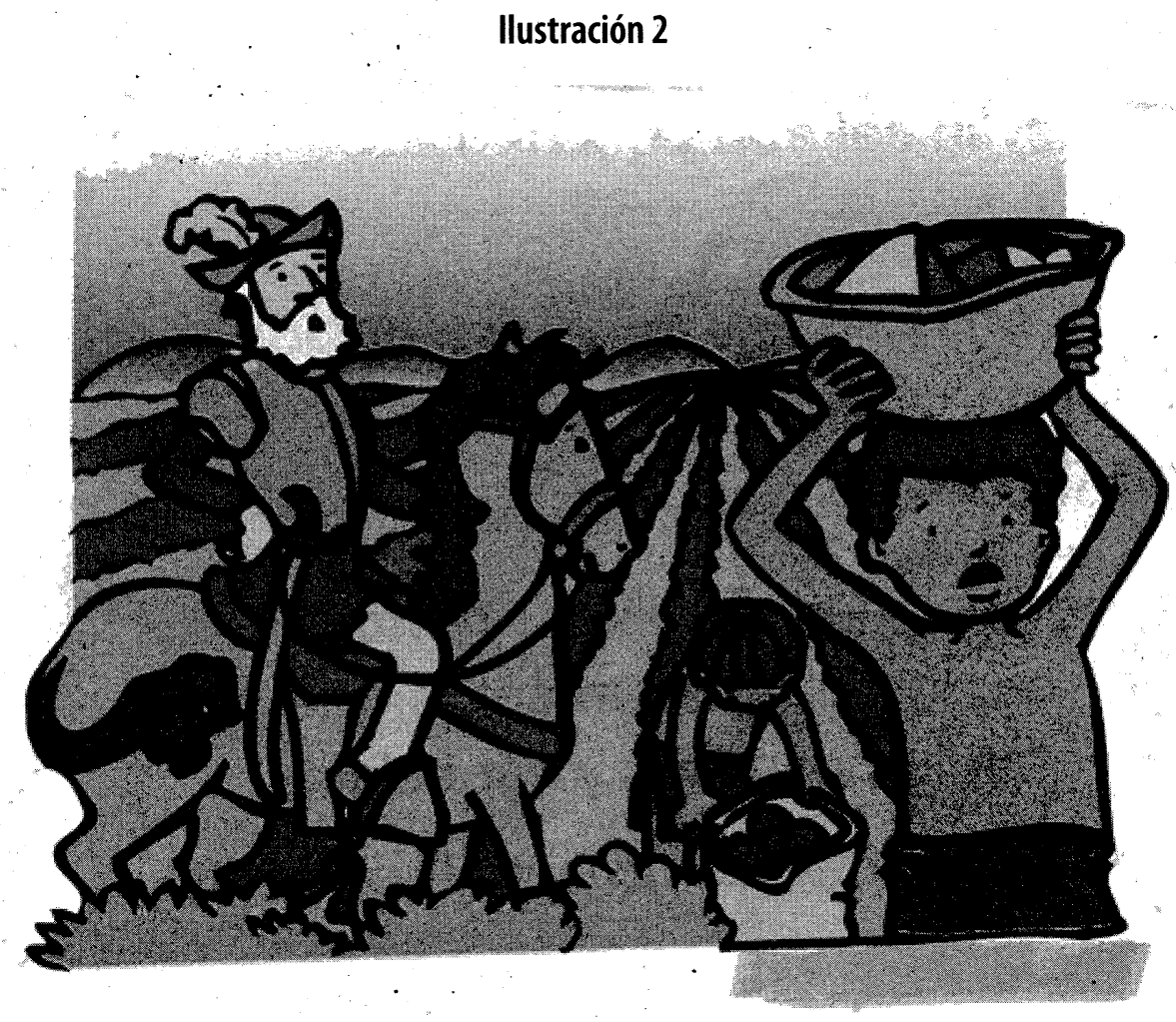

Tomado de Horizontes sociales

Ficha descriptiva

Número de ilustración: 2

Texto de donde se toma la ilustración: Prentice Hall

Año de edición: 1998

Página donde se encuentra la ilustración: 93

Tipo de ilustración: dibujo

Grado: $3^{\circ}$
Área: Ciencias Sociales integradas. Geografía Historia, Cívica

Sección: Nuestra historia

Títulos y subtítulos: La Historia. Tiempo y lugar

Textos escritos asociados a la ilustración:

"Período de la Colonia desde 1550 hasta 1810, abarca la dominación de los indígenas por parte de los españoles”. Horizontes Sociales 1999:93 
La composición de la imagen muestra que a pesar de que la representación del afrocolombiano corresponde a un primer plano, la actitud victoriosa del conquistador lo coloca por encima tanto $\cdot$ del indígena como del afro. La figura del conquistador abarca un porcentaje bastante importante del tamaño de la imagen. Por su parte, la imagen del afro es de atención y desconcierto ante la voz del conquistador.

Esta conjugación de composiciones hace de la ilustración para nada una imagen simple; desde el punto de vista de la representación, es un ejemplo denso de una imagen bastante compleja. Resalta varios aspectos, por un lado, una composición gráfica profundamente infantilizada, no por ello menos eficaz para explicar el tema del trabajo pesado; las piedras que carga el afrocolombiano da cuenta de los roles que cumpliría este grupo en la economía colonial. De esta manera se hizo la familiar la relación de este grupo con ciertos trabajos, en este caso una faena agrícola o minera.

Desde el análisis propuesto, esta imagen es otro ejemplo de las categorías movilizadas a través del orden colonial y puesto en los textos para signar una serie de valores y paradigmas urdidos en la etapa colonial con una fuerte simbología que ilustró de una manera específica a cada grupo humano. En estos términos, la ornamenta del colonizador en la ilustración 2 indica el estatus de la civilización europea; sólo esta persona está vesti$\mathrm{da}$, adornada y calzada, en contraposición a indígena y al afro que aparecen semidesnudos.

En consecuencia, la ilustración rescata de una manera caricaturesca un tema vital en las tramas del universo colonial, la labor económica que jugaron indígenas y afros en el llamado nuevo reino de granada. Esta lámina recurre a presentar los grandes bastiones en los que descansará la economía colonial y la figura decorativa que desde la hegemonía emanada por el rey de España, cumplirían los conquistadores en estas tierras. La imagen explicita los dos órdenes que cumplirían afros e indígenas en la economía colonial, los últimos dedicados a las faenas agrícolas, ya que se consideraron más débiles, en tanto los primeros serán utilizados por su fortaleza biológica en las labores más agresivas como las minas.

El tema del trabajo esclavizado hace notar una verdad por sí mismo evidente la política de los reyes de España estuvo condicionada por la búsqueda inaplazable de metales que tanto requería Europa para nutrir el naciente capitalismo. Por esta circunstancia, la primera historiografía sobre los africanos y sus descendientes versará sobre la mano de obra esclavizada, presente en autores como Juan Friede, Jaime Jaramillo Uribe, Darío Fajardo y Germán Colmenares entre otros historiadores. $\mathrm{Y}$ tal vez por eso encontramos una asociación casi automática entre las ilustraciones de los afros y el trabajo pesado.

Esta parte de la historia es bastante conocida entre los licenciados en Ciencias Sociales y tal vez por esa situación se realiza un vínculo. automático entre labores fuertes y población esclavizada. Si bien algunos textos plantean el tema de la baja demográfica de la población aborigen vs. la aparición de la población africana, este elemento no se ha destacado suficientemente en la esfera del escenario colonial. Como tampoco se explica de dónde emerge que el trabajo de un afro equivale al de 3 indios juntos; el mismo profesor Colmenares explicaba cómo el trabajo esclavo fue del orden del $75 \%$, frente al restante $25 \%$ del indígena, eso explica el porcentaje tan importante que ocupa ese tipo de ilustración en el marco del trabajo en la época colonial.

En la ilustración y la descripción escrita se nota el fortalecimiento de varios paradigmas en los imaginarios de los y las colombianas. Una primera inflexión es la coherencia entre el título donde emerge la imagen y lo que sucede en la ilustración. Se dice que esas personas llegaron a reemplazar a los aborígenes que no soportaron 
los trabajos pesados, esta manera de representar la disposición natural de este grupo para el trabajo agotador e inhumano, fortalece el imaginario que este grupo nació para el trabajò pesado y por eso durante mucho tiempo fueron considerados bestias de carga. La gráfica también oculta el reconocimiento de los instrumentos utilizados por los españoles para lograr los frutos de lo que presenta el texto como trabajo pesado.

Los trabajos pesados, actividades como la minería, cargadores humanos, ilustran de una manera importante el rol de los grupos en la etapa colonial. Sería interesante reflexionar sobre las condiciones parasitarias de los blancos o españoles y el ejercicio real de las labores que se requieren para sostener una sociedad. Lo más problemático es que esos roles se quedaron anclados en el imaginario social y los afros fueron congelados en esas actividades, situación que se va a convertir en el prototipo del trabajo afro; lo marginal, ventas callejeras o ambulantes que convierten a la gastronomía en un sitial por excelencia para esta comunidad.

\section{La otra circunstancia que ponen las imágenes en evidencia es que la trata trasatlántica es un problema de los africanos y no de historia de los colombianos.}

La falta de tratamiento del tema africano y el poco espacio en el marco del texto escolar, dejan muchísimas preguntas en el ambiente; los docentes, los niños y las niñas terminan respondiendo desde su desconocimiento y en general el de la sociedad colombiana: "pobres los negritos ${ }^{21}$ ".

El tema de lo étnico racial en Colombia, necesariamente implica preguntarse por la identidad nacional. Concebir la sociedad colombiana como derivada del cruce de tres grupos humanos ha sido punto de profundos análisis por parte de diversos autores, entre otras razones porque "la propuesta de identidad nacional se elaboró te-

\footnotetext{
${ }^{21}$ Comentarios realizados por estudiantes en varios colegios de Bogotá.
}

niendo en cuenta lo que se debía ser y para ello era necesario olvidarse de lo que se había sido" 22 .

Esta propuesta debía entronizarse a través de los textos escolares en asignaturas como Historia y Geografía principalmente. Es en ese sentido que representar a un país mestizo tiene que ver con que la herencia aborigen o afrocolombiana, no se corresponde con la propuesta de identidad colombiana. En general, la sociedad colombiana no reconoce como raíz su descendencia indígena y menos aún la africana. Frente al tema de los africanos y sus descendientes, y de acuerdo con la ideología imperante, es necesario mantener el silencio y la invisibilidad comó mecanismo fundamental para no tratar la esclavización como proceso social. Muestra de esto es que a pesar de los esfuerzos académicos señalados anteriormente existe la resistencia a plantear las sociedades americanas como poscoloniales y mucho menos como posesclavistas.

Las consideraciones anteriores implican reconocer las representaciones de làs comunidades afrocolombianas, problematizarlas y darles un lugar en la construcción de la nación. Sólo develando los roles asociados históricamente a ese grupo humano se logrará dar una visión más real de esa colectividad. De la mano de las anteriơres consideraciones es necesaria la conexión de los siguientes campos que, entre muchos otros, quedan como interrogantes importantes para una futura línea de trabajo.

\section{Conclusiones preliminares}

Como conclusión básica o fundamental se puede argumentar que los criterios bajo los cuales se han "ilustrado" a las personas afrodescendientes, siguen intactos desde el siglo XIX. La desnudez, el énfasis en ciertos rasgos fenotípicos (cabello ensortijado, labios gruesos, cadenas, grilletes) a lo cual sólo escapan un par de imágenes, pervive a pesar de que las editoriales cuenten con grupos de apoyo para la comprensión de la diversidad cultural. En consecuencia, se esperaría por lo menos lograr

${ }^{22}$ Herrera, Martha Cecilia y otros (2003). La identidad nacional en los textos escolares de Ciencias Sociales. Colombia 1900/1950. Universidad Pedagógica Nacional. Bogotá. 
una diversificación de las imágenes. De otra parte, también genera desconcierto el que a pesar del aporte historiográfico de las diversas corrientes de las Ciencias Sociales, el tratamiento de la imagen de los descendientes de africanos sea exactamente el mismo que antes de la sanción de Colombia como país multicultural.

Los textos analizados no hacen ningún tipo de referencia a cómo aparecen los africanos y sus descendientes. Por el contrario, las recurrencias. encontradas señalan que se considera normal que figuren como atavismos de la esclavización, desaparezcan de la historia nacional y vuelvan a aparecer en la Colombia actual bajo el estigma de la pobreza y el desplazamiento, sin ningún tipo de puente o nexo que vincule el tema de la esclavización y la situación presente de esas comunidades.

En los textos analizados queda un primer interrogante que tiene que ver con la naturaleza de los campos de la producción cultural que interactúan en la elaboración de esas ilustraciones. Es decir, las agencias educativas como el MEN y la Secretaría de Educación a quienes compete el diseño de las políticas educativas, emergen en el juego editorial. Sin embargo, hasta el momento sólo se sabe cuánto representa el comercio que se genera alrededor de la industria editorial pero poco se conoce cuáles son o debieran ser las regulaciones que deberían ejercer las entidades competentes. Otro aspecto tiene que ver con las bases de funcionamiento entre los autores de los textos escolares, los ilustradores y el resto del engranaje editorial para poder discernir los campos sobre los cuales habría que ejercer una mayor presión y acompañamiento. Por último, sería clave esclarecer el impacto de los lineamientos curriculares del Ministerio ${ }^{23}$ y el cambio o no en las ilustraciones a partir de la nueva reglamentación.

La gran conclusión que se saca luego de interpretar las ilustraciones de los textos escolares durante el período indicado 2000-2006, es la necesidad perentoria de adecuar los textos que circulan en el escenario educativo de manera masiva. No obstante, este replanteamiento no se logrará si se sigue asumiendo que las comunidades afro-

\footnotetext{
${ }^{23}$ Lineamientos Curriculares (2002). Ciencias Sociales, Bogotá.
}

colombianas no tienen historia y que mantenerlas atadas a los tradicionales roles y estereotipos construidos a lo largo de la historia oficial no es otra cosa que el reflejo de la discriminación racial y el racismo que impera en el país. Por otro lado, la perspectiva racializada de las imágenes reconoce tanto la topografía moral vinculada a las ilustraciones como la falta de una historia de la resistencia para enfrentar la trata y diáspora africana como parte de la historia que debe contarse en las aulas de clase del sistema educativo nacional.

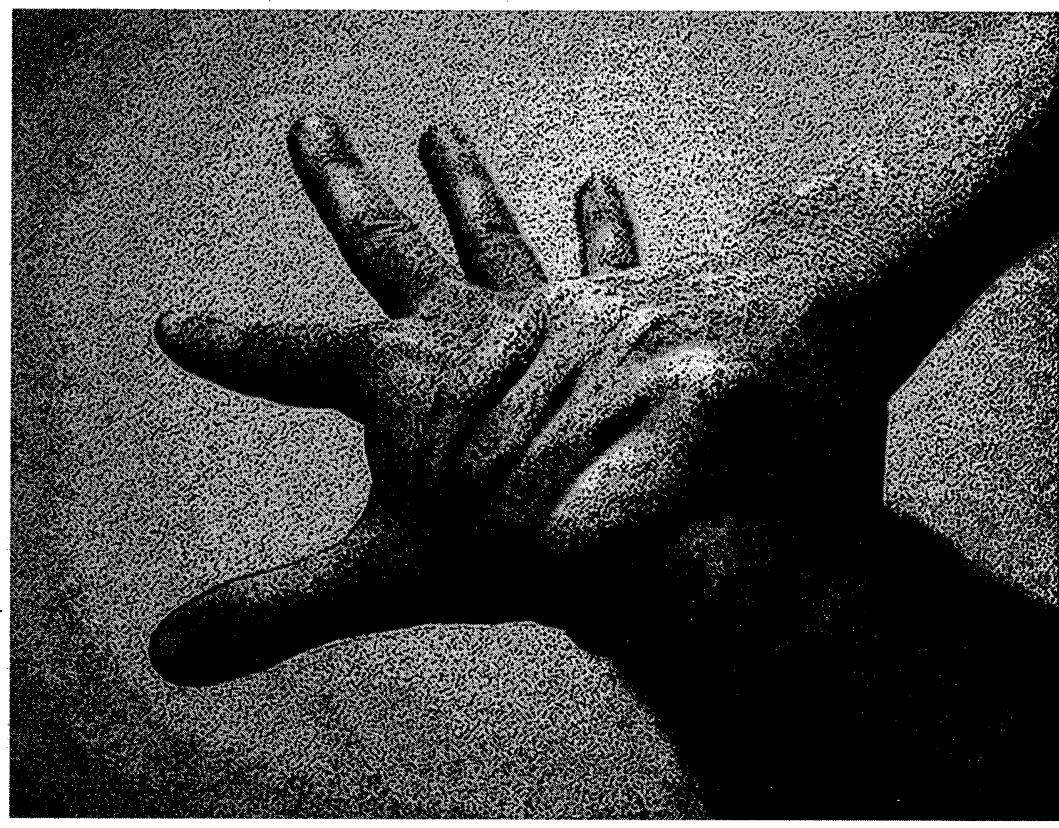

Otra posibilidad consiste en que los mismos docentes diseñen sus guías de estudio y se hagan conscientes de la necesidad de una pedagogía visual que permita poner en cuestión, las sutilezas del lenguaje visual. Por lo tanto, poner en evidencia las ilustraciones con el fin de problematizar su discurso, es una tarea fundamental y urgente para responder a los requerimientos de la Cátedra de Estudios Afrocolombianos y su respectivo proceso de implementación. Ó

\section{Bibliografía}

BORDIEU, Pierre y Jean Claude Passeron (1995). La reproducción. Elementos para una teoria del sistema de enseñanza. Editorial Grijalbo. México. 
BRION, David (1996). El problema de la esclavitud en la cultura occidental. El áncora Editores. Universidad de los Andes. Bogotá.

CAMPOS, Jaime Enrique (1999): - Horizontes sociales. Editorial Prentice Hall. Bogotá.

CHAUSTRE AVENDAÑO, Álvaro (2003). Identidades sociales 4 . Editorial Norma. Bogotá.

DÍAZ DÍAZ, Rafael Antonio (2006). África, africanismo y los estudios afrocolombianos en las Ciencias Sociales en Colombia: realidades, retos y perspectivas. En proceso de publicación. Universidad Javeriana. Bogotá.

DÍAZ RIVERO, Gonzalo (1998). Orígenes para 4o y 5o. Editorial Libros y Libres. Bogotá.

HERRERA, Martha Cecilia y otros (2003). $L a$ identidad nacional en los textos escolares de Ciencias Sociales. Colombia 1900/1950. Universidad Pedagógica Nacional. Bogotá.

LOBO, Gregory y Nick, Morgan (2003). "Lo decimos con cariño: Estratificación racial y el discurso de lo negro en Colombia: Ponencia expuesta en el XIII Congreso de colombianistas", Barranquilla, 12 al 15 de agosto de 2003. Universidad de los Andes.

GÓMEZ, Fanny.Cecilia (1995). Sociedad. Editorial Santillana. Bogotá.

MENA, María Isabel (2005). Afroamericanidad $y$ afrocolombianidad. Biblioteca de Ciencias Sociales. Editorial Voluntad. Bogotá.

Ministerio de Educación Nacional - Decreto 1122 de 1998, Reglamentario de la Cátedra de Estudios Afrocolombianos.

Lineamientos Curriculares (2002). Ciencias Sociales. Bogotá.

MOSQUERA, Juan de Dios (2004). "Integración de la afrocolombianidad al sistema edu- cativo nacional". En: Memorias de encuentro en la diversidad. Museo Nacional. Bogotá.

NOREÑA BLANCO, María Isabel (1994). Territorio y Sociedad 4. Editorial Bedout. Bogotá.

OSORIO PORRAS, Zenaida (2001). Personas ilustradas, la imagen de las personas en la iconografía escolar. Colciencias - FES, Bogotá.

PRENDES ESPINOSA, María Paz (2004). Análisis de imágenes en textos escolares, Universidad de Murcia. Barcelona.

SOLER CASTILLO, Sandra (2005). Racismo y discurso en los textos escolares. La representación de la diversidad étnica en los textos de Ciencias Sociales en Colombia. En proceso de publicación. Universidad Distrital. Bogotá.

ROJAS DE CENTENO, Inés. Elvira (1996). Civilización 3. Editorial Norma. Bogotá.

SERNA DIMAS, Adrián (2005). Ciudadanos de la geografía tropical. Ficciones bistóricas de lo ciudadano. Fondo Editorial de la Universidad Distrital. Bogotá.

TAUSSIG, Michel (2002). Chamanismo, colonialismo y el hombre salvaje. Un estudio sobre el terror y la curación. Grupo Editorial Norma. Bogotá.

WACHTEL, Nathan (1976). Los vencidos. Los indios del Perú frente a la Conquista Española (1530-1570): Alianza Editorial. Madrid.

VAN DIJK, Teun A. (1997). Racismo y análisis crítico de los medios de comunicación. Ediciones Paidós. Barcelona.

(2004). Discurso y dominación. Conferencias realizadas en la Facultad de Ciencias Humanas. Universidad Nacional de Colombia. Bogotá. 